\title{
Corrigendum
}

\section{Shifts in phytoplankton community structure modify bacterial production, abundance and community composition}

\author{
Maria T. Camarena-Gómez*, Tobias Lipsewers, Jonna Piiparinen, Eeva Eronen-Rasimus, \\ Daniel Perez-Quemaliños, Laura Hoikkala, Cristina Sobrino, Kristian Spilling \\ Aquat Microb Ecol 81: 149-170, 2018, https://doi.org/10.3354/ame01868 \\ *Corresponding author: maria.camarena@environment.fi
}

- In the Acknowledgements section on p. 167, the contribution of a financial agency and a research project was added.

- The amended Acknowledgements are given below and have been updated in the online version of the article.

Acknowledgements. This study was funded by the Walter and Andrée de Nottbeck Foundation, the Academy of Finland (decision numbers 259164 and 292711), and the Spanish Ministry of Economy and Competitiveness (CTM201459345-R) within the National Plan for Scientific and Technical Research and Innovation 2013-2016. We thank the staff at Tvärminne Zoological Station for help with the analytical measurements and sampling during the experiments. Dr. Anke Kremp is acknowledged for providing the inoculum cultures. 